\title{
Expected scores in the rod-and-frame test: Critiquing a revisit
}

DALE T. JOHNSON, CHARLES W. NEVILLE, JR., and SAMUEL N. WORKMAN, Highland Hospital Division, Duke University Medical Center, Asheville, N.C. 28801

Vaught (1970) recently criticized normative rod-and-frame test ( $R F T$ ) data obtained from psychiatric inpatients whose distribution of scores represented essentially an inversion of scores obtained from college student Ss. His criticisms were considered and discussed, and were deemed inadequate to account for the observed group differences. The need to examine individual and environment-related differences between patient and student groups to account for the inversion of RFT scores, rather than rely on somewhat temuous methodological considerations, was stressed.

Recently Vaught (1970) commented on findings (Neville, Workman, \& Johnson, 1969) that the distribution of Rod-and-Frame Test (RFT) scores for a sample of 238 psychiatric inpatients was essentially an inversion of earlier findings for college students (Pressey, 1968; Vaught, 1968). Because Vaught (1970) considered the Neville et al (1969) findings as "... not in keeping with the RFT literature," he dismissed the possibility that significant group differences may exist between college students and psychiatric inpatients and presented normative RFT data on 184 more college students that were consistent with the earlier student findings cited above. He then discussed three methodological differences between the patient and student studies which might account for the wide disparity of results, i.e., the Neville et al use of: (1) a head clamp, (2) an E-controlled rather than a S-controlled adjustment procedure, and (3) a noncommercial, rather than a commercial. PFT apparatus, with resulting calibration differences.

However, Vaught's (1970) critique seemingly fails to account for the disparity of results between the two populations. In the absence of any published data, using a head clamp to eliminate individual differences in head tilting seems more likely to be a conservative influence, since head tilting is known to displace the apparent vertical (Howard \& Templeton, 1966). Thus, a head clamp would apparently serve to remove this source of variability from patients' deviation scores, and would probably reduce them relative to student scores, rather than increase them as Vaught (1970) suggests. Lester (1968) quite critically reports, however, that 26 of 30 RFT studies reviewed made no mention of attempts to control head position.

The problem of $E$ vs $S$ control of the adjustment procedure discussed by Vaught (1970) also seems to be grossly insufficient to account for the observed differences. Indeed, the study cited as evidence for his position (Adevai, Silverman, \& McGough, 1968) showed mean RFT scores of 92 Ss for E-controlled and S-controlled RFT adjustment of $4.46 \mathrm{deg}(\sigma=3.29)$ and $3.79 \mathrm{deg}(\sigma=3.32)$, respectively. This seems hardly a basis for accounting for an inverted distribution of RFT scores that involves a mean difference of at least $5 \mathrm{deg}$ for both males and females between college students and psychiatric inpatients. Vaught further stated that ". . . the Pressey-Vaught distributions provide an accurate picture of college student responding in RFT (Series 3)" and "... before meaningful comparisons can be made [between college students and psychiatric inpatients] attention must be given to making sure that procedures do not vary from sample to sample." However, since the original RFT Series 3 (Witkin, Lewis, Hertzman, Machover, Meissner, \& Wapner, 1954) was E controlled, it would seem that the Pressey-Vaught distributions, rather than the Neville et al one, are based on deviant methodology.

Likewise, calibration of the apparatus does not appear to be a significant problem, since the patient study apparatus is and was periodically checked with a carpenter's level. For horizontal and vertical positions of both rod and frame, neither has ever been more than $1 \mathrm{deg}$, and usually less than $1 / 2 \mathrm{deg}$, out of true.

Finally, it is erroneous to state that no precedents exist for the Neville et al findings. In the RFT literature, Sugerman \& Cancro (1968) reported that, of 51 male schizophrenic nonmedicated inpatients tested with RFT Series 3 shortly after admission, $47.1 \%$ had scores under $10 \mathrm{deg}$, $52.9 \%$ over $10 \mathrm{deg}$, and $37.3 \%$ over $13 \mathrm{deg}$. Silverman (1968) reported on RFT Series 3 results for 22 male schizophrenics hospitalized 0 to 3 years, wherein $18.2 \%$ had scores under $7 \mathrm{deg}, 63.6 \%$ between 7 and $10 \mathrm{deg}$, and $18.2 \%$ over $10 \mathrm{deg}$. For 18 male schizophrenics hospitalized 6 years or more, Silverman (1968) found that 50\% had scores under $7 \mathrm{deg}, 11.1 \%$ between 7 and $10 \mathrm{deg}$, and $38.9 \%$ over $10 \mathrm{deg}$. Additionally, several other studies exist whose data, while not presented in sufficient detail to allow comparisons to the patient or student normative RFT percentage data, do indicate that psychiatric patient groups of various sorts are significantly more field dependent than students or normals (e.g., Alexander \& Gudeman, 1965; Goldstein \& Chotlos, 1965: Goldstein, Neuringer, Reiff, \& Shelly, 1968).

Thus, these studies contradict Vaught's (1970) contention that the Neville et al findings were unique and provide limited additional support for the hypothesized group differences between college students and psychiatric inpatients in RFT performance as a function of factors other than methodological differences. It is not clear what the definite mechanism might be. although direct effects of psychopathology, personality types, location-specific factors, medication effects, Self-Selection by Location interactions, etc., seem reasonable possibilities. While methodological variables not mentioned by Vaught (1970) may have affected the obtained patient distribution, such as the patients having been seated closer to the apparatus than were the students, it is felt that further investigations might more fruitfully focus on individual or environment-related differences between patient and student groups.

\section{REFERENCES}

ADEVAI, G., SILVERMAN, A. J., \& McGOUGH, W. E. Perceptual correlates of the rod-and-frame test. Perceptual \& Motor Skills, 1968, 26, 1055-1064.

ALEXANDER, J. B., \& GLDEMAN, H. E. Perceptual and interpersonal measures of field dependence. Perceptual \& Motor Skills, 1965. 20. 79-86.

GOLDSTEIN, G. \& CHOTLOS, J. W. Dependency and brain damage in alcoholics. Perceptual \& Motor Skills, 1965, 21. 135-150.

GOLDSTEIN, G., NELRINGER. C., REIFF. C. \& SHELLY. C. H. Generalizability of field dependency in alcoholics. Journal of Consulting \& Clinical Psychology, 1968. 32. 560-564.

HOWARD, I. P. \& TENIPLETON, W. B. Human spatial orientation. New York: Wiley, 1966.

LESTER. G. The rod-and-frame test: Some comments on methodology. Perceptual \& Motor Skills, 1968, 26.1307-1314.

NEVILLE, C. W.. WORKMAN, S. N., \& JOHNSON, D. T. Expected scores in the rod-and-frame test: Field dependence is where you find it. Psychonomic Science. 1969, 15 , 321-322.

PRESSEY, A. W. A reply to comments on "Figural aftereffects. illusions. and the dimension of field dependence." Psychonomic Science, 1968, 11. 364 .

SILVERMAN, J. Towards a more complex 
formulation of rod and frame performance in the schizophrenias. Perceptual \& Motor Skills. $1968.27 .1111-1114$.

SUGFRMAN. A. A.. \& CANCRO, R. Field independence and outcome in schizophrenia: A U-shaped relationship. Perceptual \& Motor Skills, 1968, 27, 1007-1013.

VAUGHT, $G$. M. Expected scores in the rod-and-frame test: Fuel for the
Immergluck-Pressey fire, Psychonomic Science, $1968,13,248$.

VAUGHT, G. M. Expected scores in the rod-and-frame test revisited. Psychonomic Science, $1970,18,111$.

WITKIN, H. A., LEWIS, H. B., HERTZMAN, M. MACHOVER, K., MEISSNER, P. B., \& WAPNER, S. Personality through perception. New York: Harper, 1954.

\title{
NLM strength and CVC-CVC response-time recall*
}

\author{
HOWARD I. THORSHEIM $\dagger$ \\ University of Illinois, Urbana, Ill. 61801
}

One hundred and twenty Ss were tested for the effect of natural language mediator (NLM) strength on the retention of NLMs and paired-associate response terms over 1 week. Hypotheses were that stronger NLMs would be retained best, as would the response terms of their pairs. At three different sessions, Ss (1) generated NLMs to $50 \mathrm{CVC}$ pairs, (2) learned 18 of the pairs by a drop-out procedure and had an immediate retention test, and (3) had a 1-week retention test. The main experimental group practiced the pairs along with their NLMs in Session 2, while two groups practiced only the pairs. Two amounts of practice in Session 2 was also a variable. Results were that (1) practice of pairs with their NLMs increased the frequency of NLM recall, (2) NLM and response term recall were both a function of amount of practice, and (3) presence of the NLM during Session 2 practice facilitated recall only in the immediate test.

Natural language mediators (NLMs) consist of idiosyncratic associations between new material to be learned and past language habits (Adams, 1967). Montague, Adams, \& Kiess (1966) established NLMs as a potent variable for the long-term retention of paired associates when the NLMs are remembered. However, they found that $73 \%$ of the NLMs formed in acquisition were forgotten by the time

\footnotetext{
*This experiment is based on a dissertation submitted to the Graduate College of the University of Illinois in partial fulfillment of the requirements for the $\mathrm{PhD}$ degree in psychology. The thesis was under the supervision of Jack A. Adams. The research was supported by Grant MH-12022 from the U.S. Public Health Service.

+ Now at St. Olaf College, Northfield, Minnesota 55057.
}

of a recall test $24 \mathrm{~h}$ later, and, if the NLM was forgotten, the probability was low that the criterion response would be recalled. Because NLMs appear to be a major factor in retention, and yet are themselves responses that are susceptible to forgetting, means of increasing the retention of NLMs must be found if an increase in the long-term retention of criterion responses is to be achieved.

The purpose of the present experiment was to examine the relationship of NLM strength to NLM retention and paired-associate response term retention. NLMs are responses, and their strength can be manipulated by practice and be indexed by their empirical probability during paired-associate learning and recall.

\section{PROCEDURE}

All $S s$ in the experiment underwent three separate sessions. In Session 1 they generated NLMs to $50 \mathrm{CVC}$ pairs of $26.0 \%$ mean associability as scaled by Montague \& Kiess (1968). Each $S$ was required to form a NLM for every pair and did so. In Session 2, Ss practiced $18 \mathrm{CVC}$ pairs to a criterion of either one $(\mathrm{C} 1)$ or three $(\mathrm{C} 3)$ correct recalls per item, followed by an immediate retention test. One week after Session 2, all Ss returned for Session 3, which was another retention test just like the one immediately following Session 2 . Three main treatment groups were involved. Treatment 1 (T1) was the experimental group that had NLMs present in acquisition for practice, and Treatments 2 and 3 (T2 and T3) to control for specific and nonspecific transfer effects from Session 1 to Session 2. Combined factorially with $\mathrm{T} 1, \mathrm{~T} 2$, and $\mathrm{T} 3$ were the two levels of the practice criterion, $\mathrm{C} 1$ and C3.

In detail, $40 \mathrm{Ss}$ in $\mathrm{T} 1$ each generated a NLM for each of 50 CVC pairs in Session 1. The time required to form a NLM ranged from 2 to $65 \mathrm{sec}$, but Ss were unlimited in the time they could take. For Session 2, which was held 1 week after Session 1, 18 CVC pairs were selected at random from the set of 50 pairs. In Session 2, the 18 pairs were practiced and learned along with their idiosyncratic NLMs from Session 1. Half of the T1 Ss had Practice Criterion $\mathrm{Cl}$ and half had Practice Criterion C3. Practice Criterion C1 consisted of one correct response recall per item in a drop-out procedure differing from that described by Battig (1965) only in that the NLM generated by each S in Session 1 was typed on the card along with the item for the study portion of the trial. Thus, practice was as follows: (1) All 18 items were presented one at a time together with the idiosyncratic NLM generated for each item by $S$ in Session 1, (2) next, only the stimulus terms of each pair were presented one at a time and $S$ was tested for his ability to spell the appropriate response term correctly, (3) items for which $\mathrm{S}$ correctly recalled the response term were dropped, (4) $S$ was then shown the balance of the items in the shortened deck of cards together with the corresponding NLMs, for another study opportunity, in a new random order. The Practice Criterion $\mathrm{Cl}$ was defined as being met when $S$ had correctly recalled each response term once after as many such study-test presentations as necessary had occurred. The Practice Criterion C3 consisted of repeating the procedure until three correct response recalls had occurred for each pair.

The immediate-retention test was given 